\title{
Violencia Intrafamiliar (VIF): una breve revisión
}

\author{
Intra-family Violence (IFV): A brief review
}

DOI: 10.33539/consensus.2019.v24n2.2325

Nancy Marlene Tofenio Moreyra ${ }^{1}$

\section{RESUMEN}

El presente trabajo de investigación tiene el propósito de realizar una búsqueda bibliográfica sobre la violencia intrafamiliar, tratando de tener una mirada más cercana que nos permita comprender este flagelo que afecta actualmente a la sociedad, debido a que la violencia se ha convertido en una forma de interrelación entre los miembros de la familia. Se realizará una revisión de distintos autores de diferentes países, ya que este hecho es una característica común al interior de muchas familias que se convierten en lugares peligrosos para los miembros más vulnerables, que históricamente son los niños y las mujeres; adicional a ello, se revisarán las consecuencias del maltrato a nivel físico, psicológico y neurológico.

\section{Palabras Clave}

Violencia, familia, violencia intrafamiliar, violencia familiar en el Perú, consecuencias del maltrato

\section{ABSTRACT}

The purpose of the present research work is to conduct a bibliographic search about intrafamily violence, trying to have a closer look that allows us understand this scourge that currently affects society, due to the violence has become a form of interrelation between family members. A review of different authors from different countries will be conducted, since this fact is a common feature within many families that become dangerous places for the most vulnerable members, which historically are children and women. In addition, the consequences of abuse at a physical, psychological and neurological level will be reviewed.

\section{Keywords}

Violence, family, intra-family violence, family violence in Peru, consequences of abuse

1 Licenciada en Psicología. Estudios de Maestría en Psicodiagnóstico en Niños y Adolescentes, Universidad Femenina del Sagrado Corazón - UNIFÉ 


\section{INTRODUCCIÓN}

La violencia intrafamiliar es una realidad que viven miles de familias en nuestro país. Las estadísticas nos hablan de un incremento constante en las denuncias por maltrato al interior de los hogares, tan solo en el mes de enero del año en curso se reportaron 14491 casos de violencia en diversas modalidades (familiar, de género y sexual) lo cual "representa un incremento del $46 \%$ con respecto al mismo periodo del año pasado", Programa Nacional Contra la Violencia Familiar y Sexual (PNCVFS, 2019).

Lo que más llama la atención es precisamente que estos hechos suceden al interior de las familias que paradójicamente se convierten en un lugar inseguro y violento para muchos niños, adolescentes, mujeres y ancianos.

Martínez, López, Díaz y Teseiro (2015), en el artículo que dan cuenta de su investigación realizada en Matanzas, Cuba, durante el año 2013, mencionan que el maltrato provoca deterioro al interior de las familias. Siguiendo la misma línea, Miljánovich et al. (2013) indican que, para la sociedad, el maltrato es un asunto que se da de manera privada, al interior de las familias y que no debería trascender de ella.

La familia es la primera institución socializadora, en donde el niño establece los primeros vínculos $\mathrm{y}$, por ende, aprende a socializar. A través de las vivencias y el ejemplo, el niño aprenderá la forma de interactuar con los demás, en función del predominio de la razón sobre las emociones y el respeto de la dignidad e individualidad del otro. En suma, siguiendo a Ríos (2018), lo que el individuo aprende durante sus primeros años quedará impregnado en él por el resto de su existencia. Es decir, establecerá los parámetros bajo los cuales el nuevo ciudadano se vinculará con sus pares.

En función de lo expuesto anteriormente, el objetivo del presente artículo de revisión es consultar diversas referencias académicas que permitan un acercamiento al tema de la violencia intrafamiliar.

\section{MÉTODO}

Para la búsqueda bibliográfica, se recurrió a bases de datos como EBSCO, SciELO, Dialnet, Redalyc y también a bibliotecas virtuales. La búsquedas en tales fuentes bibliográficas se realizó con las palabras clave: violencia, familia, violencia intrafamiliar, violencia familiar en el Perú y consecuencias del maltrato.

Se consultaron estudios realizados en el Perú y en otros países latinoamericanos. Del total de artículos seleccionados, el 70\% con una antigüedad no mayor a 5 años.

\section{DESARROLLO}

En el contexto actual, las imágenes de niños flagelados, abusados o quemados por algún miembro de su familia son comunes en la televisión, periódicos o las redes sociales; igualmente las denuncias de mujeres golpeadas por sus parejas o los índices de feminicidios en diferentes ciudades constituyen manifestaciones de una violenta realidad que sucede al interior de las familias. Ello se refleja en los datos registrados por el Programa Nacional contra la Violencia Familiar y Sexual (PNCVFS, 2019) en los Centros Emergencia Mujer 
(CEM) de todo el país. Sin embargo, esta situación no es exclusiva del Perú, es una realidad que comparte con muchos países, Barbosa, Marcela, Daría y Rivera (2017); Díaz, Arrieta y González (2015); Quintero (2017).

La violencia intrafamiliar (VIF) es un flagelo que afecta a numerosas familias en diferentes estratos socioeconómicos y culturales e implica una serie de acciones $u$ omisiones que dañan a uno o más miembros del grupo familiar y que es cometido por algunos de sus integrantes, generalmente el padre.

Para Martínez, Ochoa y Viveros (2016), la VIF es el resultado de "estilos de vida" que tuvieron su origen en la familia donde fueron criados los padres, es la forma de relacionarse que algunos hogares adoptan y es la aceptación del sometimiento como algo inevitable, la normalización de la violencia como una manera de asentar la jerarquía del hombre. Esta idea es reforzada por Montero, Delis, Ramírez, Milán y Cárdenas (2011) y Maneiro, Gómez-Fraguela y Sobral (2016) quienes mencionan que los hijos de una familia maltratadora cuando crezcan repetirán la misma conducta, pues aprendieron que las dificultades y las diferencias se solucionan a través de la violencia, es decir hablan de la transmisión intergeneracional del maltrato.

Yugueros (2014) menciona que la transmisión de la violencia se garantiza por los mitos y estereotipos de género, lo mismo aseguran Barbosa et al. (2017) y Martínez et al. (2015) quienes mencionan que muchas conductas son aprendidas como producto de un sistema social violento que ha moldeado las conductas de sus integrantes.
Es un fenómeno que se da en todas las culturas y épocas, de ello deja constancia Quintero (2017) en su artículo "Violencia Familiar en los orígenes de la sociedad Rioplatense", quien menciona que los registros históricos del siglo XVIII hacen referencia a documentos judiciales concernientes a juicios entablados por esposas, a sus cónyuges, acusándolos de VIF. Menciona también que la mujer, siglos atrás, era considerada inferior $\mathrm{y}$ el hombre era quien debía conducirla y disciplinarla empleando el castigo físico y la violencia, si hacía falta. Barbosa et al. (2017) coinciden en señalar que la VIF ha existido en diferentes épocas y culturas, pero difieren con Quintero (2017) al afirmar que en otras épocas no se denunciaba.

Díaz et al. (2015) consideran que el machismo y la violencia que se generan al interior de las familias, son inherentes a muchos núcleos familiares y han estado presentes a lo largo de la historia de la humanidad.

Estas conductas vienen reforzadas, a decir de Ríos (2018), por las estructuras sociales patriarcales firmemente arraigadas en la sociedad y ello contribuye a la cosificación de la mujer quien se convierte en una especie de propiedad de la cual el hombre puede disponer a su antojo; en este aspecto coincide también Quintero (2017) cuando manifiesta que la violencia en el hogar está anclada en el concepto de patriarcado. Lorente (2004), citado por Yugueros (2014), menciona que la mujer es maltratada por la pareja para dejar claramente delimitado su rol de sumisión y subordinación ante él.

Medina, Arévalo y Durán (2015) indican en función de los estudios realizados sobre el tema, que los niños varones son educados con rigor y "disciplina" para evitar la 
expresión de sus emociones naturales por ser consideradas como propias del sexo femenino. Ellos deben expresar su fuerza y poder por medio de la violencia ya que es necesario demostrar quién manda.

Sin embargo, es preciso recordar que la familia es considerada como la célula básica de la sociedad y, a decir de Ríos (2018), es la instancia donde el ser alcanza su calidad humana y es dentro de la familia donde la persona establece los primeros vínculos $\mathrm{y}$, por ende, aprende a socializar. A través de las vivencias y el ejemplo, el niño aprenderá la forma de interactuar con los demás en función del predominio de la razón sobre las emociones y el respeto de la dignidad del otro. En suma, siguiendo a Ríos (2018), lo que el individuo aprende durante sus primeros años quedará impregnado en él por el resto de su existencia.

Arriagada (2007, citada por Guirado et al., 2011), señala que la familia es el lugar a donde se debería acudir en búsqueda de refugio y apoyo, donde el individuo debería encontrar seguridad y contención en momentos difíciles. No obstante, contrario a lo que se espera, actualmente el ámbito familiar es un lugar inseguro y violento para muchos niños, adolescentes, mujeres y ancianos.

De esta manera, la familia paradójicamente se convierte en un lugar de refugio e indefensión, baluarte y hostilidad (Guirado et al., 2011). Un campo de enfrentamiento donde la concentración de poder es unilateral y además cruel, un lugar hostil y amenazante en contraposición a lo que se espera (Ríos, 2018), ya que es al interior de las familias donde se golpea, humilla, descalifica, agrede y ataca sexualmente a los más débiles e indefensos.
La VIF es un "fenómeno social que impacta la seguridad de gran cantidad de hogares" y "atenta contra la vida, la dignidad, la integridad" (Guirado et al., 2011, p.13) física, emocional y mental de algunos de sus miembros. Ese impacto se revela en las cifras que reportan las denuncias recibidas en los 346 CEM de todo el país. Tan solo en el mes de enero del año en curso se reportaron 14491 casos de violencia en diversas modalidades (familiar, de género y sexual) lo cual "representa un incremento del $46 \%$ con respecto al mismo periodo del año pasado".

Con respecto a los niños y adolescentes menores de 17 años, se registraron 1874 casos de violencia psicológica, 1187 de violencia física y 793 de violencia sexual; Y en cuanto a las mujeres se evidenció 5018 casos de violencia psicológica, 4328 de violencia física y 411 de violencia sexual, PNCVFS (2019).

Y según el diario Correo, entre enero y julio del presente año se denunciaron 4789 casos de violencia familiar en las 8 comisarías de la División contra la Violencia Familiar en Lima. Villa El Salvador es el distrito con más incidencias: 1322 casos (548 casos de violencia psicológica, 526 de violencia psicológica y física y 140 de violencia física), el segundo distrito es Independencia con un total de 1031 casos.

En el período enero-agosto 2019, 99700 mujeres fueron víctimas de violencia familiar y sexual. De ese total, $35 \mathrm{mil}$ son niñas y adolescentes, 6 mil entre las edades de 0 a 5 años, 14 mil entre los 6 y 11 años y 15 mil entre los 12 y 17 años, PNCVFS (2019). Las cifras no son exactas para revelar el porcentaje preciso de niños y adolescentes víctimas de violencia 
sexual porque no es un tema del que se pueda hablar abiertamente por el estigma social que conlleva, es por ello que un alto porcentaje de estos casos se conocen cuando años después del suceso, la víctima acude a terapia ya que las secuelas que deja son duraderas.

Históricamente, el agresor es el padre, esposo o conviviente quien, según Miljánovich et al. (2013), evidencia conductas agresivas originadas en una infancia caracterizada por maltrato físico y psicológico, esta huella quedó impregnada en su ser y la reproduce casi de manera inconsciente. Para Vega (1998), el hombre considera el castigo como único recurso para corregir conductas inadecuadas o para lograr que se le obedezca, expresa su poder a través de la dominación del maltrato y la mujer acepta tal actitud como natural ya que en la mayoría de las veces también proviene, en su infancia, de un hogar maltratador y debido también a su dependencia económica que deviene progresivamente en dependencia emocional. La mujer, sin percatarse de ello, ingresa a un círculo de maltrato del cual le es difícil salir sin apoyo.

En España, Yugueros (2014) refuerza este aspecto al mencionar que la mujer evidencia características propias del estrés postraumático, permanece en un estado de desconcierto que no le permite actuar de manera racional y adecuada, no percibe la agresión ya que ha generado dependencia y la soporta por tiempo prolongado pues considera que su pareja actúa de esa forma porque ella lo "provoca" y que con el tiempo va a cambiar de actitud.

Medina et al. (2015) hacen mención a diversos estudios y entrevistas con hombres maltratadores quienes referían experiencias negativas durante su infancia con respecto a su familia de origen, recordaban maltrato en la modalidad de castigo físico o verbal en contra de sus madres y de ellos mismos así como abandono de sus padres; fueron criados con la consigna de no expresar miedo, dolor o expresar emociones consideradas como propias del sexo femenino (ternura o vulnerabilidad); adicional a ello Miljánovich et al. (2013) mencionan que esa situación generó en los hombres dolor, miedo, inseguridad y resentimiento que más tarde expresaron en conductas agresivas dirigidas hacia su pareja o hijos debido a que cuando eran niños no podían descargar el miedo, dolor y frustración contenidos contra el adulto agresor $\mathrm{y}$, al crecer, esas emociones reprimidas encuentran las condiciones necesarias y suficientes para plasmarse en la relación de pareja.

Sin embargo, aunque el uso de la fuerza se ha ligado históricamente al varón debido a la testosterona, la fisiología humana revela que la mujer presenta también estas reacciones (Ríos, 2018). Una conducta violenta reducida a su expresión fisiológica se explica de la siguiente manera: en circunstancias de tensión emocional la adrenalina se eleva, ello provoca que el organismo incremente la presión sanguínea y el ritmo cardíaco, lo cual va a detonar en violencia buscando la regulación del organismo. Entonces, en un hogar donde es escaso el respeto y el trato igualitario entre sus miembros, las situaciones de tensión emocional son frecuentes, por ello, también los hechos de violencia son constantes (Ríos, 2018).

Debido a que la violencia implica el uso del poder para doblegar la voluntad del 
otro, implica también conflictividad; entonces, el mundo actual individualista, egoísta, narcisista, que busca el placer, la satisfacción inmediata de los deseos, sin considerar los derechos, necesidades y deseos del prójimo, se ve envuelto en la tríada: Poder-Violencia- Conflictividad; este planteamiento le corresponde a Ríos (2018).

La VIF adopta diversas modalidades, sin embargo, cualquiera de ellas afecta la integridad física, emocional y mental de la víctima que generalmente es el miembro más indefenso, desvalido, joven o anciano.

Guirado et al. (2011) clasifican la violencia intrafamiliar en función del destinatario de los hechos violentos como sigue:

- Conyugal: Es aquella que se produce en contextos de una relación de pareja y generalmente la víctima es la mujer (Guirado et al., 2011). La Organización de la Naciones Unidas (ONU) declaró en 1993 como actos de violencia en contra de la mujer "toda acción que cause sufrimiento físico, psicológico o sexual".

- Infantil-Adolescente: Cualquier forma de abuso o maltrato que cause en el niño o adolescente daño físico o emocional. El abandono físico y emocional también es una forma de maltrato. Los agresores son los padres o cuidadores quienes consideran el empleo de la violencia como una forma de corrección.

- Adultos mayores: Incluye toda forma de maltrato de parte de algún miembro de la familia. Teniendo en cuenta la dependencia, determinada por la edad avanzada del anciano. Con respecto a las formas de maltrato están el maltrato físico, psicológico, sexual, abandono, negligencia y abuso económico.

- Para Guirado et al. (2011) el maltrato hacia las personas con Discapacidad o Necesidades especiales también constituye otra forma de violencia al interior de la familia, en este caso, la víctima es un integrante discapacitado o con Necesidades Especiales. Verdugo (2004), citado por Guirado et al. (2011), señala 3 razones por las cuales la familia comete estos actos:

1) Sentimientos de culpa o fracaso.

2) Estrés relacionado con alteraciones en las rutinas y dinámica familiar.

3) Alteraciones en la economía y presupuesto familiar.

Debido a que el maltrato es una situación adversa y estresante que deja secuelas físicas, emocionales y neurológicas en las víctimas, podemos encontrar en la literatura varias referencias y estudios que se han llevado a cabo con mujeres y niños víctimas de maltrato (Vega, 1998; Ocampo, 2015; Aiquipa, 2015; Amores-Villalba y Mateos-Mateos, 2017).

Hay que tener en cuenta que la infancia es la etapa del desarrollo más sensible a estos efectos negativos ya que el cerebro y la personalidad del niño están aún en pleno desarrollo, por lo que cuanto más se agreda a un niño durante su infancia serán mayores las posibilidades de que luego desarrolle conductas agresivas o trastornos del estado de ánimo en la adolescencia o adultez, como lo resaltan Miljánovich et al. (2013) en su trabajo de investigación.

Igualmente, Amores-Villalba y MateosMateos (2017) consideran en su artículo 
que el maltrato puede alterar el desarrollo neurológico y causar déficits cognitivos permanentes.

Los avances científicos nos permiten conocer más acerca de la evolución cerebral desde el momento de la concepción hasta la edad adulta, y como este proceso, aunque esté determinado por el genoma humano, avanza y se desarrolla adecuadamente en función de las influencias del ambiente en el que se desarrolla el individuo; estas condiciones favorecerán o interferirán en el desarrollo cerebral, Amores-Villalba y Mateos-Mateos (2017). Estos mismos autores indican, en función de diversos estudios, que el maltrato infantil origina pérdida acelerada de neuronas, retrasos en la mielinización y alteraciones en la poda neuronal lo cual puede explicar el perfil cognitivo y conductual de los niños maltratados, caracterizado por excesivas reacciones de miedo, percepción de amenaza del ambiente, problemas de conducta, agresividad, pasividad, apatía, tristeza, empatía disminuida, dificultades de aprendizaje, menor desarrollo intelectual, dificultades en la memoria y atención, alteraciones del estado de ánimo, mayor comorbilidad psiquiátrica y dificultades en el ajuste social en la vida adulta $y$, en función de la cantidad de tiempo que el niño ha sido maltratado, será mayor o menor el grado de deterioro de sus funciones cognitivas y afectivas.

Miljanovich et al. (2013) hacen referencia también a las dificultades escolares, nerviosismo y problemas de conducta. Heleniak et al. (2016, citados por AmoresVillalba y Mateos-Mateos, 2017) indican que la manera en que un niño aprende a regular su conducta y sus emociones es a través del aprendizaje social de los patrones y modelos que reciba de sus padres o cuidadores, si estos evidencian reacciones hostiles o de rechazo e ignorancia ante las expresiones emocionales del niño, este no aprenderá a regularlos adecuadamente por miedo al castigo o rechazo.

Del mismo modo, Martínez et al. (2015) mencionan que los niños maltratados evidencian trastornos de atención $\mathrm{y}$ concentración, trastornos de adaptación y fobias específicas.

Con respecto a las consecuencias del maltrato en la mujer, Aiquipa (2015), Martínez et al. (2015) y Vega (1998) mencionan la dependencia emocional, subordinación y sumisión, temor, ansiedad, estrés permanente, baja autoestima, ambivalencia, sentimiento de indefensión, internalización de la culpa y de la opresión, aislamiento, minimización del abuso, dificultades para interrelacionarse con otras personas, minimización de sus capacidades cognitivas, frustración y, producto de ello, en numerosas ocasiones, tiende a golpear a sus hijos garantizándose de esta manera la perpetuidad del maltrato. Adicional a lo aludido, Miljánovich et al. (2013) señalan que la mujer soporta el maltrato ya que está condicionada por creencias religiosas respecto a la indisolubilidad del matrimonio, a pesar de que se produce un deterioro en su personalidad y alteraciones orgánicas (cefaleas, parálisis facial) y sintomatología depresiva; también mencionan un hecho resaltante y es que la mujer acepta la situación de maltrato como un hecho inevitable debido a que ha interiorizado la cultura del maltrato.

Montero et al. (2011) mencionan, además, que la mujer violentada presenta trastornos del deseo y la respuesta sexual, trastornos 
orgánicos como úlceras, presión alta, infarto, asma. Ocampo (2015) menciona también aislamiento, retraimiento, irritabilidad, desinterés por actividades que antes le resultaban agradables.

En ese mismo orden de ideas, Díaz et al. (2015) mencionan que las consecuencias del maltrato en la mujer son amplias y abarcan la afectación de su salud física y mental, así como la de sus hijos; estos autores consideran, además, que la mujer podría presentar tensión nerviosa, ataques de pánico y trastornos del sueño.

Yugueros (2014) añade también que la mujer víctima de maltrato durante años actúa, al parecer, de forma irracional cuando retira la denuncia interpuesta en contra de su agresor e incluso retoma la relación con él porque se encuentra en un estado de desconcierto llamado estrés postraumático, tal estado no le permite actuar apropiadamente. Este mismo autor añade que la mujer maltratada manifiesta sentimientos de desvalorización, inseguridad, incapacidad e impotencia para terminar con la situación de maltrato.

\section{DISCUSIÓN}

La violencia intrafamiliar es modelada al interior de la familia, los niños observan las interacciones que se establecen en su hogar y estas se instauran en ellos de manera permanente, así lo reflejan los estudios desarrollados por Martínez et al. (2015), Miljánovich et al. (2013) y Montero et al. (2011). Igualmente, autores como Ríos (2018), Barbosa et al. (2017), Medina et al. (2015) y Yugueros (2014), concuerdan que estos patrones aprendidos por los niños se repetirán en el futuro al momento de formar familia
La violencia intrafamiliar ha existido en diferentes épocas y culturas, según Quintero (2017) en Argentina; Barbosa et al. (2017) en Colombia y Aiquipa (2015) en Perú; sin embargo, existe contradicción en cuanto a la afirmación de que en épocas antiguas el maltrato no era denunciado, por lo menos así lo afirman Barbosa et al. (2017); en contraposición, Quintero (2017) realizó una investigación de los registros judiciales que dejan constancia de las denuncias realizadas en los siglos XVIII y XIX por mujeres maltratadas por sus cónyuges en Buenos Aires.

Los autores coinciden también en otro aspecto muy importante y es el hecho de que la mujer es percibida como un objeto de propiedad del hombre (Ríos, 2018; Quintero, 2017; Medina et al., 2015).

Por otro lado, contrario a lo que se espera de la familia, ella se ha convertido en un lugar peligroso para sus miembros más desvalidos, muchos autores no dudan en afirmar ello y, al hacerlo, coinciden al unísono (Guirado et al., 2011; Miljánovich et al., 2013; Yugueros, 2014 y Ríos, 2018).

Igualmente, los autores consultados coinciden unitariamente al referirse a las consecuencias que deja la VIF en las víctimas (Vega, 1998; Miljánovich et al., 2013; Ocampo, 2015; Medina et al., 2015; Yugueros, 2014; Aiquipa, 2015; Díaz et al., 2015; Martínez et al., 2016; AmoresVillalba y Mateos-Mateos, 2017). Con respecto a los niños, estos mismos autores, mencionan las dificultades de aprendizaje, menor desarrollo intelectual, dificultades en la atención, concentración y memoria, problemas de conducta, agresividad o pasividad, empatía disminuida, dificultad para regular sus emociones en el presente 
$\mathrm{y}$ en el futuro, también porque aquí volvemos al punto mencionado líneas arriba y es que los patrones de conducta se instauran durante los primeros años de vida. Con respecto a las mujeres, se habla de dependencia emocional, estrés permanente, subordinación, baja autoestima, minimización del abuso, deterioro de sus capacidades cognitivas, aislamiento, deterioro de su personalidad, trastornos orgánicos, etc.

\section{CONCLUSIONES}

- La familia se convierte en un lugar peligroso para sus integrantes más indefensos porque la concentración de poder es unilateral y se expresa de manera cruel.

- La violencia intrafamiliar ha estado presente en los núcleos familiares en todas las épocas y culturas.
- La violencia intrafamiliar se transmite generacionalmente ya que muchas conductas son aprendidas en el seno de la familia.

- Los maltratadores tuvieron una infancia caracterizada por el maltrato.

- Las consecuencias de la violencia al interior de las familias en los niños se refleja en menor desarrollo cerebral, dificultades de aprendizaje, de conducta y afecta también los procesos de atención, concentración y memoria.

- En la mujer violentada, se aprecia dependencia emocional, temor, estrés permanente, baja autoestima, deterioro de su personalidad y alteraciones orgánicas. 


\section{REFERENCIAS}

Aiquipa, J. (2015). Dependencia emocional en mujeres víctimas de violencia de pareja. Revista de Psicología, 33(2), 411-437. Recuperado de //www.scielo.org.pe/pdf/psico/ v33n2/a07v33n2.pdf

Amores-Villalba, A. y Mateos-Mateos, R. (2017). Revisión de la neuropsicología del Maltrato infantil: La neurobiología y el perfil neuropsicológico de las víctimas de Abusos en la infancia. Psicología educativa, 23(2), 81-88. https://doi.org/10.1016/j. pse.2017.05.006

Barbosa, A., Marcela, G., Daría. J. y Rivera, E. (enero - julio, 2017). Reflexión socioconstruccionista y política en torno a la violencia familiar. Tesis Psicológica, 12(1), 116-126. Recuperado de https://www.redalyc.org/articulo.oa?id=139057282005

Díaz, S.,Arrieta, K. y González, F.(febrero, 2015). Violencia intrafamiliary factores de riesgo en mujeres afrodescendientes de la ciudad de Cartagena. Revista clínica de medicina de familia, 8(1), 19-30. http://dx.doi.org/10.4321/S1699-695X2015000100004

Guirado, K., Caraballo, J., González, O., Rangel, J., Ramírez, R., Dávalos, J., Ochoa, J., Alpacedo, E. y Brito, E. (2011). Violencia intrafamiliar. Recuperado de http://www2. congreso.gob.pe/sicr/cendocbib/con4_uibd.nsf/420C52281A3F7DA9052580CF005A FA91/\$FILE/pdf_204.pdf

Maneiro, L., Gómez-Fraguela, J. y Sobral, J. (julio-diciembre, 2016). Maltrato Infantil y violencia familiar: exposición dual y efectos de la transgresión adolescente. Revista Mexicana de Psicología, 33(2), 11-120. Recuperado de https://www.redalyc.org/ pdf/2430/243056044003.pdf

Martínez, M., López, A., Díaz, A. y Teseiro, M. (2015). Violencia intrafamiliar y trastornos psicológicos en niños y adolescentes del área de salud de Versalles, Matanzas. Rev.Med. Electrón, 37(3), 237-245. Recuperado de: http://scielo.sld.cu/scielo.php?script=sci_ar ttext\&pid=S1684-18242015000300006

Martínez, N., Ochoa, M. y Viveros, E. (enero-junio, 2016). Aspectos subjetivos relacionados con la violencia intrafamiliar. Caso municipio de Sabaneta, Antioquia. Estudios sociales, 24-25(47), 348-376. Recuperado de http://www.scielo.org.mx/ scielo.php?script=sci_arttext\&pid=S0188-45572016000100348

Medina, A., Arévalo, A. y Durán, A. (2015). Necesidades, expectativas y sueños sobre la relación de pareja en hombres remitidos para atención psicológica por denuncias de violencia intrafamiliar. Universitas Psychologica, 14(1). doi:10.11144/Javeriana. upsy13-5.nesr

Miljánovich, M., Huerta, R., Campos, E., Torres, S., Vásquez, V., Vera, K. y Díaz, G. (2013). Revista de Investigación en Psicología, 16(1), 29-44. doi: https://doi.org/10.15381/ rinvp.v16il.3918

Montero, E., Delis, M., Ramírez Pérez, R., Milán, A. y Cárdenas, R. (2011). Realidades de la violencia familiar en el mundo contemporáneo. Medisan, 15(4), 515-525. Recuperado de https://www.redalyc.org/pdf/3684/368445229016.pdf 
Programa Nacional Contra la Violencia Familiar y Sexual. Ministerio de la Mujer y Poblaciones vulnerables. Informe estadístico. (2019). Recuperado de https://www. mimp.gob.pe/contigo/contenidos/pncontigo-articulos.php? $\operatorname{codigo}=80$

Ocampo, L. (2015). Autoestima y adaptación en víctimas de maltrato psicológico por parte de la pareja. Psicología desde el Caribe, 32(1), 145-168. Recuperado de http:// rcientificas.uninorte.edu.co/index.php/psicologia/article/viewFile/5204/9148

Quintero, G. (2017). Violencia familiar en los orígenes de la sociedad Rioplatense, Buenos Aires 1785- 1829. Cuadernos de la Facultad de Humanidades y Ciencias SocialesUniversidad Nacional de Jujuy, 51, 111-121. Recuperado de https:/www.redalyc.org/ pdf/185/18554668009.pdf

Ríos, G. (2018). Enfoque criminológico de la violencia de género e intrafamiliar ¿Es eficaz la respuesta penal? Vox Juris, 37(1), 67-78. Recuperado de https://www.aulavirtualusmp. pe/ojs/index.php/VJ/article/view/1439

Vega, J. (diciembre, 1998). El problema de las mujeres que sufren maltrato en la relación de pareja. IPSI Revista de Investigación en Psicología, 1(2), 75 - 98. doi: https://doi. org/10.15381/rinvp.v1i2.4831

Yugueros, A. (2014). La violencia contra las mujeres: conceptos y causas. Baratia. Revista Castellano-Manchega de ciencias sociales, 18, 147-159. Recuperado de https://www. redalyc.org/pdf/3221/322132553010.pdf

Fecha de recepción: 30-09-2019

Fecha de aceptación: 31-10-2019 